\title{
Rules of song development and their use in vocal interactions by birds with large repertoires
}

\author{
NICOLE GEBERZAHN and HENRIKE HULTSCH \\ Institute of Biology, Department of Behavioural Biology, Free University of Berlin \\ Haderslebener Str. 9, 12163 Berlin, Germany
}

Manuscript received on January 15, 2004; accepted for publication on February 5, 2004.

\begin{abstract}
Songbirds are well known for settling their disputes by vocal signals, and their singing plays a dominant role. Most studies on this issue have concentrated on bird species that develop and use small vocal repertoires. In this article we will go farther and focus on examples of how species with large song repertoires make use of their vocal competence. In particular, we will outline the study of interaction rules which have been elucidated by examining time- and pattern-specific relationships between signals exchanged by territorial neighbors. First we present an inquiry into the rules of song learning and development. In birds with large song repertoires, the ontogeny of such rules proceeds along a number of trajectories which help in understanding the often remarkable accomplishments of adult birds. In both approaches, our model species will be the Common Nightingale Luscinia megarhynchos that has been investigated intensively in the field and in the laboratory.
\end{abstract}

Key words: song development, developmental trajectories, interaction by song, vocal duels, Common Nightingale.

\section{INTRODUCTION}

The ontogenetic development of singing shows a number of characteristic traits that are widespread across oscine birds (Marler 1991). In the typical case, the early phase of auditory learning is segregated from the phase of vocal production by an interval of several weeks. Vocal activity of the young bird then covers another time span, often lasting for several months. Early in life, birds perform temporally coherent arrays of vocalizations that first are structurally amorphous and only gradually improve in form and structure. Vocalizations are highly variable in the juvenile singing, and have been compared to the playful activities found in young mam-

Correspondence to: Nicole Geberzahn

E-mail: nicozahn@zedat.fu-berlin.de mals. Referring to the profile of the developmental progress, Marler and Peters (1982a) have suggested a tripartite model which distinguishes among (a) subsong, (b) several stages of plastic song and (c) crystallized fullsong. We will outline how the study of these stages allows us to identify a set of ontogenetic trajectories.

Then we consider how birds use their vocal competence later in life. The singing of adult birds occurs in a fascinating variety of forms. For example, it can be given as a solo performance or as a chorus of many different voices, or it can take place as a display between two interacting individuals. During dyadic encounters birds can perform their songs alternatingly or one of them may overlap a song of his neighbor (Hultsch and Todt 1982). 
These forms of song performance prompt questions about whether and how far they are related to a mutual exchange of messages. Here we consider these issues in birds that develop and use a large repertoire of different song-types. These birds have a number of options for responding to each other, thus making their interactions particularly interesting (review in Todt and Naguib 2000).

Our model species will be the Common Nightingale Luscinia megarhynchos, thereafter referred to as nightingale. Males of this species acquire and use a large vocal repertoire (about 200 discretely different song-types), and extensive field studies have been conducted on both its nocturnal and diurnal singing. Furthermore, studies of the acquisition and development of song in handraised birds allow us to explain a number of phenomena obtained from field experimentation.

\section{SONG DEVELOPMENT}

The subsong of birds consists of soft and rambling vocalizations which are structurally amorphous and rather difficult to analyze. Therefore, the next stage in vocal ontogeny, plastic song, is the preferred subject of investigators who search for rules of pattern development. In nightingales that have a particularly extended period of vocal ontogeny, plastic singing starts at an age of about eight months, i.e. in January. Then, first precursors of acquired imitations can be discerned and with time an increasingly larger number of song-type precursors can be identified (Fig. 1). The completion of the repertoire of song-type precursors takes a period of several weeks. During this process, imitations of master songs that birds had heard early in life do not emerge earlier than imitations of other songs that they had experienced later during the tutoring. In other words, the temporal order of song-type production does not reflect the temporal order of auditory acquisition.

In nightingales, ontogenetic trajectories can be discerned both within and between songs, with progression occuring on different hierarchical levels. Trajectories expressed at the intra-song level con- cern the following traits. During early stages of ontogeny, birds often sing incomplete songs; i.e. some song constituents may be missing (cf. Fig. 1). In addition, the serial succession of song sections may be inverted. For example the final trill-section of a song may be produced ahead of the normally preceding note complex. Thus, the intra-song syntax is not initially stereotyped. At the same time, however, the structure of patterns is sufficiently elaborated to allow for easy identification of song-type precursors. In other words, pattern phonetics takes its adult form ahead of the intra-song syntax, which 'crystallizes' only at about 10 months of age. Interestingly, the phonetic or syntactic quality of those imitations that emerge only late in ontogeny is not inferior to the quality of imitations produced earlier (Fig. 2). This suggests a developmental trajectory which does not build on vocal 'experience' with a particular output, but concerns a general progression in motor competence or skill (Hultsch 1989, 1993).

Besides trajectories concerning the pattern structure of vocalizations, ontogenetic progression also proceeds in the temporal domain of singing. As both the duration of vocal compounds as well as their temporal segregation have to be shaped, trajectories in the time domain are highly interrelated and follow complex rules (Hultsch and Todt 2000). The adult time structure of singing (songs alternating with silent intervals of about the same duration) is the last performance feature to crystallize and the adult form is achieved only at an age of about 11 to 12 months.

There are also rules of development at higher levels of song organization. They concern the relationships between song patterns, i.e. the inter-song level. For example, imitations that, in the adult performance, occur as clusters of sequentially associated song-types (members of a song-type package) emerge, quite consistently, together in time. In addition, throughout ontogeny these precursors of imitations are sequentially associated in the same way as in the adult singing (Hultsch 1989). On the other hand, progression at a still higher level, i.e. the sequential association of different packages, seems de- 


\section{Tutored song-types ( week 3)}
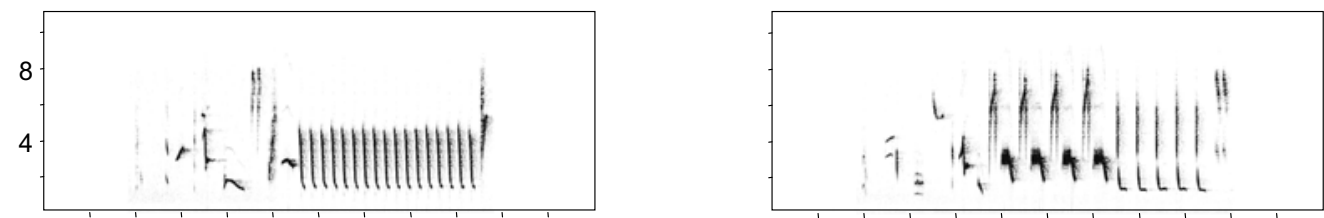

Precursors of imitations - plastic song, week 35
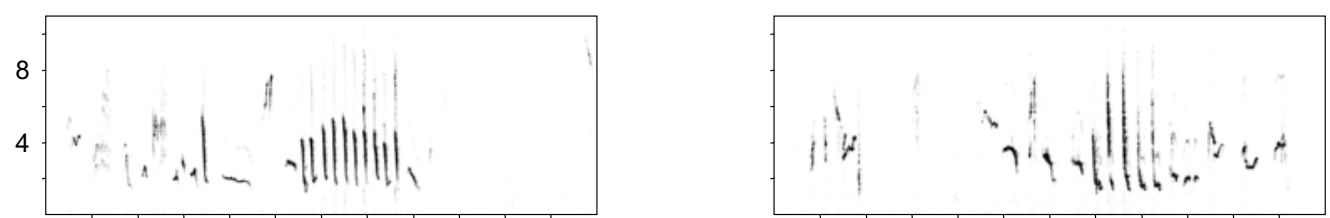

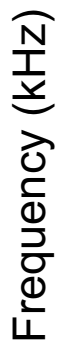

week 39
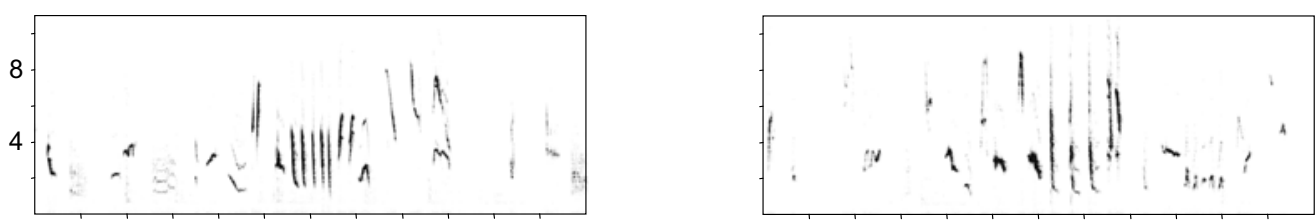

week 41
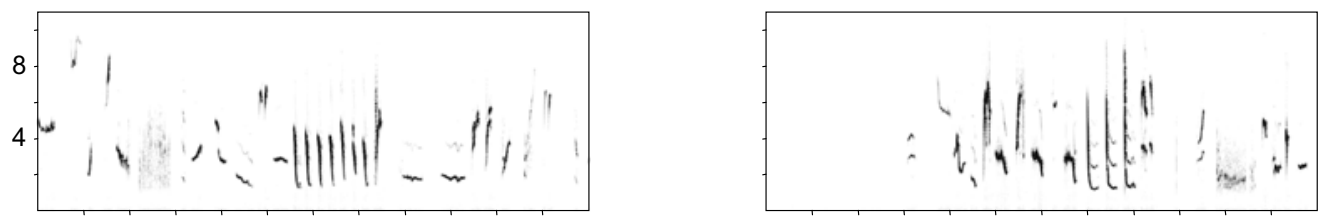

Imitations - crystallised song, week 48
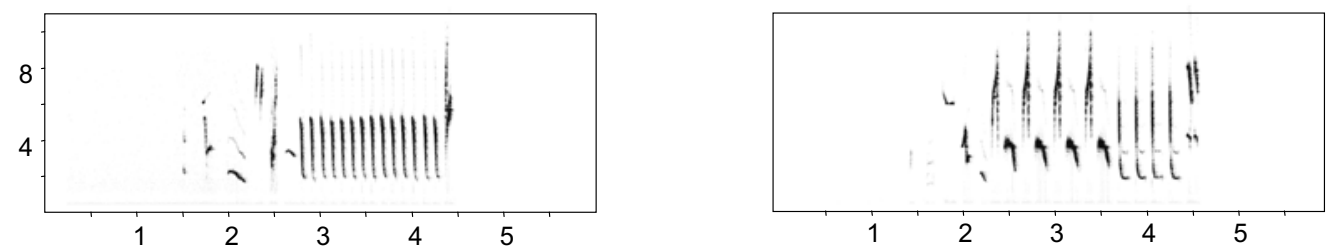

Time (s)

Fig. 1 - Spectrograms of two tutored nightingale song-types (top), precursors of imitations (middle) and crystallized imitations (bottom). 


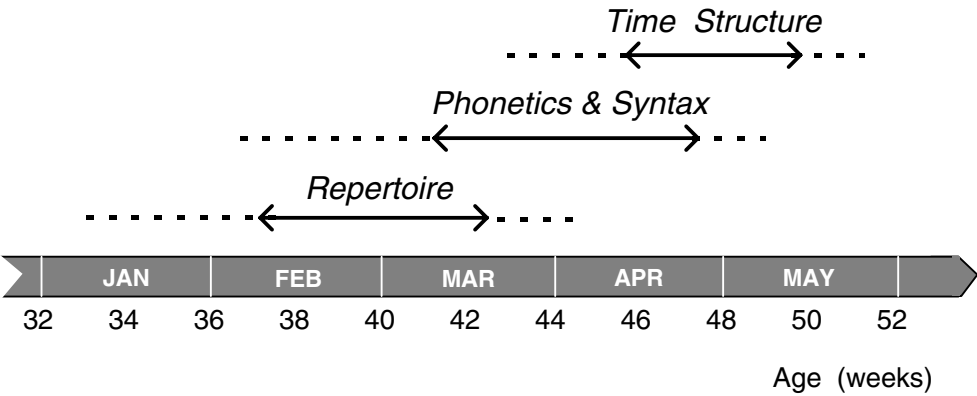

Fig. 2 - The time course of three ontogenetic trajectories assessed during the song development of Common Nightingales. The solid lines bounded by arrows give the core age during which the respective song characteristics show most rapid progression. To contrast the trajectory of pattern structure against the development of repertoire and time structure its two aspects (phonetics and syntax) are lumped here, although pattern phenotypes develop ahead of pattern syntax.

layed and in fully-grown form these so called 'context groups' can only be assessed close to the time of song crystallization. However, the time structure of singing gives some indication of context groups earlier in ontogeny. During the phase of continuous vocal production, for example, the intervals between imitations acquired from the same master string or context group were significantly shorter than intervals found when the birds switched to imitations of another context group (Hultsch 1993). Thus at the inter-song level, the early ontogeny of song material already reflects hierarchical properties of the songtype association groups.

The development of singing is not simply a process by which a bird improves the quality of acquired song material by vocal rehearsal. At least two further characteristics merit consideration. One of them enlarges the repertoire of a bird, whereas the other one has the opposite effect. In nightingales, increasing the repertoire size is much more pronounced than decreasing it (Todt and Hultsch 1996, Geberzahn et al. 2002). Repertoire enlargement is achieved by either acquiring additional song-types, or by developing new recombinations or, finally, inventing novel songs.

In bird species called 'open-ended' or 'ageindependent learners' (Marler and Peters 1987), fur- ther learning can occur during the phase of plastic singing or even later in life (Hultsch 1989, 1993, Todt and Geberzahn 2003). Learning beyond the early sensitive phase explains observations obtained for birds that, instead of being housed in isolation, are housed together, thus allowing them to vocally interact with each other. Here the composition of song repertoires and also the performance preferences of shared song-types clearly converge. Thus, additional learning coupled with a shaping of the performance towards convergence can lead to a sharing of at least parts of repertoires among conspecific neighbors (Hultsch and Todt 1981, Slater 1989, Marler and Nelson 1993, Lemon et al. 1994, Geberzahn et al. 2002).

A different strategy of repertoire enlargement that, in contrast, enhances the vocal individuality of a songster, is the development of new recombinations or novel inventions of songs. Nightingales, for instance, may generate individual specific songtypes by recombining parts of imitated songs in a novel way. Interestingly, such recombinations are limited to material of song-types associated within the same package group (Hultsch 1993). In addition, nightingales may develop song-types not represented in what they have heard during the tutoring, and so are completely new. During both ontogeny 
and adult singing, genuine inventions occur as coherent subsets in the singing, which results in an alternation of performance phases containing acquired imitations or novel inventions (Hughes et al. 2001).

Upon reaching the final stage of song development (crystallization) birds may reduce their song-type repertoire. This phenomenon is especially marked in species that use only small songtype repertoires as adults (Marler and Peters 1982b, Nelson et al. 1995). In nightingales, repertoire constriction is much less conspicuous; only about five to eight percent of imitations identified in the course of song development are discarded from the final repertoire. During the phase of plastic singing, these song-types are produced with a rather poor copy quality (Hultsch 1991). Thus, the ontogenetic 'history' of eventually discarded song-types makes repertoire constriction a quite interesting issue in nightingales, too.

The stability and persistence of song patterns can vary remarkably across species. Aside from birds, such as nightingales, that hardly modify their patterns (Kipper et al. 2004), there are other species where individuals may change quite radically. Starlings Sturnus vulgaris (Eens et al. 1992) and Domestic Canaries Serinus canaria (Nottebohm and Nottebohm 1978), for example, may modify their song repertoires from year to year.

\section{THE SINGING OF ADULTS AND THEIR INTERACTIONS}

Interactive song exchanges have been examined from both formal and functional points of view. From a formal perspective, relationships that exchanged signals shown in the time and/or the pattern domain are studied (Hultsch and Todt 1982, Wolffgramm and Todt 1982). From a functional perspective, song interactions are specified in terms of social relationships among signalers and distinguish, for example, behaviors between partners such as mates, or behaviors between rivals such as territorial neighbors. In some species mated birds interact by performing elaborated vocal duets (Todt et al. 1981, Farabaugh 1982), whereas rivals typically engage in forms of counter-singing, i.e. vocal duels (Todt 1970, 1981, Krebs et al. 1978, Kroodsma 1979, Nielsen and Vehrencamp 1995). Here we will deal with vocal interactions among territorial neighbors and describe how their responses in the time and the pattern domains are related to functional aspects.

\section{Responses IN The Time Domain}

Many animals avoid simultaneous production of vocal signals. In songbirds such avoidance behavior can be observed as a segregation of performance times (including heterospecific avoidance) on a larger scale and as an alternation of songs on a finer scale. A basic functional aspect of signal alternation is the use of temporal signal displacement as a strategy to prevent the own vocalizations from being masked acoustically (Cody and Brown 1969, Ficken et al. 1974, Hultsch and Todt 1982). Temporal adjustment is especially clear during the nocturnal singing of nightingales and can be specified as follows.

In a population of territorial birds, individuals exist which - during dyadic singing - preferentially start their songs shortly after a neighbor has terminated his preceding song. Such subjects are called 'inserters' or 'alternators'; they are distinguished from 'overlappers', which prefer to start their songs some time before a neighbor has finished a preceding song. Still other individuals do not obviously adjust their songs to a neighbor's vocalization, but rather seem to follow their temporal self-program. These birds are called 'autonomous songsters' (Hultsch and Todt 1982). There is evidence that these three types of behavior cannot simply be explained as individual idiosyncrasies, but rather reflect different socially interactive roles. Application of the role concept here is appropriate for two reasons. First, each 'role' reflects a specific strategy that is used in relation to season and social context, and second, depending on season and context, individuals may change their 'role'.

The three roles seem to serve different functions. Autonomous singing, for instance, occurs especially in males with a well-established territory 
and thus may be related to dominance status. Inserting, on the other hand, is a more common strategy which obviously serves acoustic avoidance, mutual listening, signal detection and responding. Overlapping, finally, is predominantly found at the beginning of the territorial season, and allows a bird to challenge or even repel a competitor, mainly by jamming another bird's signals and so presenting a vocal threat (Todt 1981, Hultsch and Todt 1982, Naguib and Todt 1997).

Studies of the significance of temporal interaction strategies led us to examine the mechanisms by which temporal adjustment is controlled. It turned out that in overlappers song onset latencies were rather precisely tuned to the timing of song onset in the other male, and in inserters to the song ending in the other male. In both overlappers and inserters, latencies peaked at about $1 \mathrm{~s}$, showing that birds are indeed listening and responding to each other (Hultsch and Todt 1982). This conclusion was substantiated by interactive playback experiments that examined the inserter role in more detail. Both the latency with which stimulus songs were broadcast after each song utterance of the test bird and the duration of the stimulus songs were varied. The results revealed an impressive flexibility in the temporal adjustment of the test bird (Fig. 3). Furthermore, there was a striking after-effect following the playback trials: the normal timing of song delivery was not immediately resumed. Rather we found that there were prolonged intersong intervals for a couple of songs, before these gradually relapsed to normal duration. Such behavior suggests that the bird was 'waiting' for another song from the rival to occur. In line with findings from other playback experiments, these effects can not be explained by simple stimulus/response mechanisms. Rather they point to basic motivational variables, like being in an 'interactive state', underlying the diverse facets of temporal interactions.

\section{Responses in the Pattern Domain}

During singing interactions, territorial songbirds tend to modify the patterning of their performance

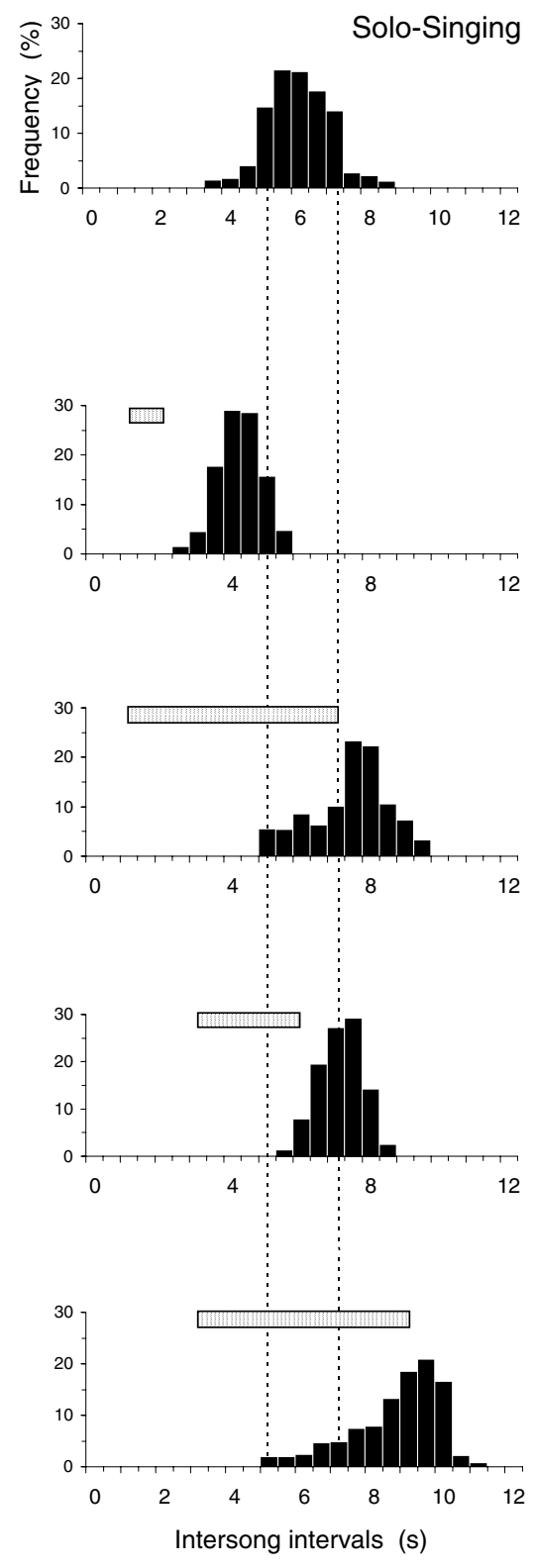

Fig. 3 - Frequency histograms of intersong interval durations assessed in a nightingale, that was exposed to interactive playback experiments during his nocturnal singing. The top histogram gives interval durations in his undisturbed solo-singing, the lower ones those assessed during the stimulation. The time when the bird had terminated a given song is set as 'Zero'. Referring to 'Zero' the inserted horizontal bars indicate the onset and duration of the stimulus songs. Each of the lower histograms gives the pooled responses for a certain stimulus onset latency (1s or $3 \mathrm{~s}$ ) and stimulus duration (1s, 3s or 6s). After Hultsch 1980. 


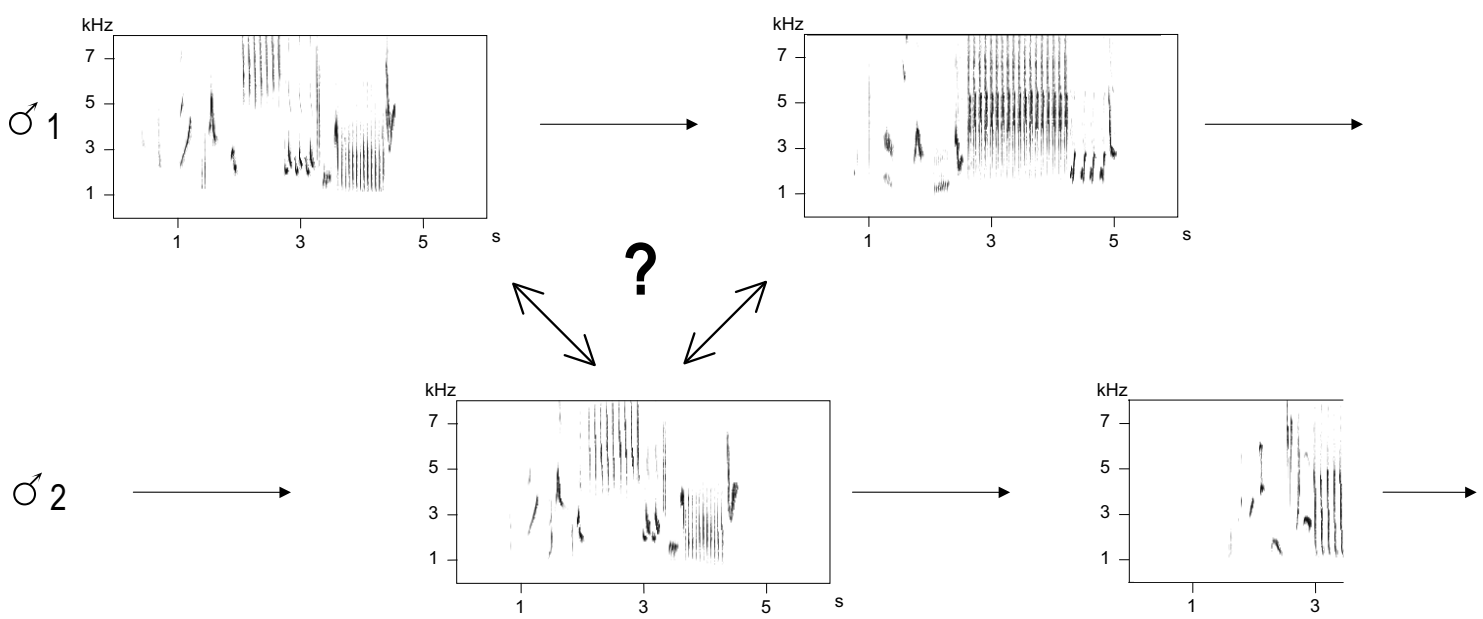

Fig. 4 - Spectrograms of songs produced during an interaction by two neighboring Common Nightingale males. Here, both males alternate their songs, and male 2 gives a song-type matching response to the first song of male 1 .

and such responses show tonic or phasic properties. As a tonic response, a male may alter the quality of his singing gradually over an extended span of time, for instance by increasing the volume or duration of his songs. As a phasic response, in contrast, a bird selects a particular song type of his own repertoire and vocalizes this song as a reply to a stimulus song (cf. Fig. 4). Examples of this form of responding are song matching, convalent responding and coordinated switches between bouts of songs.

Song matching is widespread across species and particularly impressive in songsters which sing with 'immediate variety' (e.g. A-B-C-D-), like Eurasian Blackbirds Turdus merula (Todt 1970) or Common Nightingales (Hultsch 1980). Coordinated song type switching, on the other hand, is found in species that sing with 'eventual variety', repeating renditions of a particular song type several times before starting to sing another one (e.g. AA-A-A-B-B-B-.), like Abyssinian Ground Thrushes Zoothera piaggiae (Todt 1971b), Song Sparrows Melospiza melodia (Kramer et al. 1985), Western Meadowlarks Sturnella neglecta (Falls and d'Agincourt 1982) and Great Tits Parus major (McGregor et al. 1992).

Pattern-specific responses also build on prerequisites in the vocal repertoires of the interacting in- dividuals, depending on the species. This dependence is particularly evident in song matching. By definition, during song matching (syn.: 'equivalent response') a song $X_{1}$ is responded to by a song with an equivalent pattern $X_{2}$. Thus matching can occur only between individuals who share song-types in their vocal repertoires. If, in addition to sharing parts of their repertoire, individuals also have corresponding sequential associations among song-types, they may interact with convalent responses (syn.: 'vocal supplementing'). Here a stimulus song $X$ is responded to by a song $Y$ which can be regarded as a sequential continuation of $X$. Convalent responding may have an interesting outcome, because it allows a male to become the 'sequential leader' in a vocal interaction (Todt 1971a, 1975, Todt and Hultsch 1980, 1996). Interactions involving convalent responses are particularly impressive displays and the role of 'vocal leader' has been shown to bear some advantages in a contest (Naguib et al 1999).

Given the remarkable differences that species show in various aspects of their singing it is not surprising that several hypotheses have been proposed to explain the proximate functions of patternspecific responses in vocal interactions (review in Todt and Naguib 2000). For vocal matching, which to date is the most extensively studied response, 
such hypotheses range from straightforward ones, like 'addressing an opponent' (Todt 1975, Hultsch and Todt 1986) or 'sending a keep-out signal' (Falls et al. 1982, McGregor et al. 1992, Shackleton and Ratcliffe 1994), to more controversial ones like 'distance estimation' (Krebs et al. 1978, Naguib 1997) or 'attracting the attention of a third party', like females or other males (Todt 1981, Todt and Naguib 2000).

The basic 'addressing' interpretation of vocal matching is a candidate mechanism to deal with the general problem of signaling to a particular male in a community of songsters. The interesting point is that a more specific message of the signal can be encoded in its timing, as has been shown in nightingales and blackbirds (Hultsch and Todt 1986). These species use song matching in two temporally different forms. In rapid matching, a matcher overlaps the other male's song. In delayed matching, in contrast, the matcher waits until the other bird has ended his song rendition and inserts his response into the intersong interval of his counterpart. The message implied by rapid matching is similar to the one described for temporal overlapping, i.e. a vocal threat. Rapid matching is especially dominant at the beginning of the singing season when songsters set up territories and have highly agonistic interactions. In contrast, delayed matching can be found particularly when territories are established and when other song features of neighbors indicate that they sing in a more relaxed way. Therefore it was interpreted as a vocal 'greeting ritual' (Todt 1981).

From a functional perspective, it is important in vocal interactions not to sacrifice the salience of a signal and hence to keep its occurrence at an optimal level. This explains why vocal interactions, like many other kinds of signal exchange, are not perpetuated during the entire time when two neighbors are singing in parallel, but rather occur sporadically. From a proximate perspective, on the other hand, the length of interactional phases seems to be limited by the properties of a bird's endogenous program of song delivery (self-program), which may in turn constrain the ease of access or retrieval of a particular vocal pattern in response to what is heard from another bird.

\section{CONCLUSION}

Analyses of time- and pattern-specific relationships between exchanged songs reveal that birds perform differentiated forms of vocal interaction. We have shown that vocal interaction builds on certain prerequisites, like sharing of song repertoires, if vocal matching is to occur. If neighbors share additional properties of their repertoires, such as associations among particular types of song, patterns of specific vocal interaction may be extended to include convalent responses. We can reasonably assume that vocal learning plays a crucial role in establishing the basis of such vocal interactions, as studied by asking how nightingales acquire and develop their vocal competence. In so doing, we found that there is much more to song ontogeny than just the perfection of a vocal skill. It also serves to establish vocal memory that results in the sharing of repertoires and singing programmes, providing an inventory that is the basis for interaction by song.

\section{ACKNOWLEDGMENTS}

We like to thank Dietmar Todt for his effective support of our research on nightingales, and Friederike Schleuß for her valuable cooperation. We are also grateful to a number of other people, too many to name here, who provided skillful help in handraising our birds, performing experiments or conducting data analyses. Last, but not least, we appreciated the kind invitation to the IBAC conference in Belém. The study was supported by the DFG (Az.: To 13/30-1), and N.G. received a research fellowship of the City of Berlin.

\section{RESUMO}

Pássaros canoros são bem conhecidos por resolver suas brigas através de sinais vocais e seu canto tem um papel dominante. A maioria dos estudos sobre este assunto focalizou espécies de aves que desenvolvem e usam repertórios vocais pequenos. Neste artigo iremos mais longe, examinando como espécies com grandes repertórios fa- 
zem uso de suas capacidades. Descreveremos particularmente o estudo das regras de interação que foram desvendadas pelo exame das relações temporais e estruturais entre os sinais trocados por vizinhos. Inicialmente, investigamos as regras de aprendizagem e desenvolvimento do canto. Nas aves com grande repertório vocal, a ontogênese dessas regras segue certas trajetórias que ajudam a entender o desempenho dos adultos, geralmente notável. Em ambas abordagens, nossa espécie-modelo será o Rouxinol-comum Luscinia megarhynchos, que foi pesquisado intensamente no campo e no laboratório.

Palavras-chave: desenvolvimento do canto, trajetórias de desenvolvimento, interação pelo canto, duelos vocais, Rouxinol-comum.

\section{REFERENCES}

Cody ML and Brown JH. 1969. Song asynchrony in chapparal birds. Nature 222: 778-780.

Eens M, Pinxten R and Verheyen RF. 1992. Song learning in captive European Starlings, Sturnus vulgaris. Anim Behav 44: 1131-1143.

FAlls JB ANd D'Agincourt LG. 1982. Why do meadowlarks switch song-types? Canad J Zool 60: 3400-3408.

Falls JB, Krebs JR and McGregor PK. 1982. Song matching in the Great Tit Parus major: the effect of similarity and familiarity. Anim Behav 30: 977-1009.

FARABAUgh SM. 1982. The ecological and social significance of duetting. In: Kroodsma DE AND Miller EH. (Eds), Acoustic communication in birds. New York: Academic Press, p. 85-124.

Ficken RW, Ficken MS and Hailman JP. 1974. Temporal pattern shift to avoid acoustic interference in singing birds. Science 183: 762-763.

Geberzahn N, Hultsch H AND Todt D. 2002. Latent song type memories are accessible through auditory stimulation in a hand-reared songbird. Anim Behav 64: 783-790.

Hughes M, Hultsch H and Todt D. 2001. How do birds learn when they learn to sing? Imitation and invention in nightingale song. Ethology 108: 35-48.

Hultsch H. 1980. Beziehungen zwischen Struktur, zeitlicher Variabilität und sozialem Einsatz im Gesang der Nachtigall, Luscinia megarhynchos. PhD Thesis, FU Berlin.
Hultsch H. 1989. Ontogeny of song patterns and their performance mode in nightingales. In: ERBER J, Menzel R, Pflüger J and Todt D. (Eds), Neural Mechanisms of Behaviour. Stuttgart: Thieme, p. 113.

Hultsch H. 1991. Correlates of repertoire constriction in the song ontogeny of Nightingales (Luscinia megarhynchos). Verh Dtsch Zool Ges 84: 474.

Hultsch H. 1993. Tracing the memory mechanisms in the song acquisition of birds. Neth J Zool 43: 155-171.

Hultsch H And TodT D. 1981. Repertoire sharing and song post distance in nightingales. Behav Ecol Sociobiol 8: 182-188.

Hultsch H AND TodT D. 1982. Temporal performance roles during vocal interactions in nightingales. Behav Ecol Sociobiol 11: 253-260.

Hultsch H AND TodT D. 1986. Zeichenbildung durch mustergleiches Antworten. Z Semiotik 8: 233-244.

Hultsch H And TodT D. 2000. Developmental Trajectories of Complex Signal in Animals: The Model of Birdsong. In: Weissenborn J AND HöHLE B. (Eds), Approaches to Bootstrapping. Amsterdam and Philadelphia: John Benjamins, p. 309-331.

Kipper S, Mundry R, Hultsch H and Todt D. 2004. Long term persistence of song performance roles in nightingales. Behaviour 141: in press.

Kramer HG, Lemon RE and Morris MJ. 1985. Song switching and agonistic stimulation in the Song Sparrow (Melospiza melodia). Anim Behav 33: 135-149.

Krebs JR, Ashcroft R and Webber M. 1978. Song repertoires and territory defence in the Great Tit. Nature 271: 539-542.

Kroodsma DE. 1979. Vocal dueling among male Marsh Wrens: Evidence for ritualized expressions of dominance/subordinance. Auk 98: 506-515.

Lemon RE, Perrault S and Weary DM. 1994. Dual strategies of song development in American Redstarts, Setophaga ruticilla. Anim Behav 47: 317329.

Marler P. 1991. Differences in behavioural development in closely related species: bird song. In: BATEson P. (Ed), The development and integration of behaviour. Cambridge: University Press, p. 41-70.

Marler P And Nelson D. 1993. Action-based learning: 
a new form of developmental plasticity in bird song. Neth J Zool 43: 91-101.

Marler P ANd Peters S. 1982a. Structural changes in song ontogeny in the Swamp Sparrow, Melospiza georgiana. Auk 99: 446-458.

Marler P And Peters S. 1982b. Developmental overproduction and selective attrition: New processes in the epigenesis of birdsong. Dev Psychobiol 15: 369-378.

Marler P And Peters S. 1987. A sensitive period for song acquisition in the Song Sparrow, Melospiza melodia: a case of age limited learning. Ethology 76: 89-100.

McGregor PK, Dabelsteen T, Shephard M and Pedersen SB. 1992. The signal value of matched singing in Great Tits: evidence from interactive playback experiments. Anim Behav 43: 987-998.

NAGuib M. 1997. Ranging of songs in Carolina Wrens: effects of familiarity with the song-type on use of different cues. Behav Ecol Sociobiol 40: 385-393.

Naguib M and Todt D. 1997. Effects of dyadic vocal interactions on other conspecific receivers in Nightingales. Anim Behav 54: 1535-1543.

Naguib M, Fichtel C and Todt D. 1999. Nightingales respond more strongly to vocal leaders in simulated dyadic interactions. Proc R Soc Lond B265: 537-542.

Nelson DA, Marler P and Palleroni A. 1995. A comparative approach to vocal learning: intraspecific variation in the learning process. Anim Behav 50: 83-97.

Nielsen BMB and Vehrencamp SL. 1995. Responses of Song Sparrows to song-type matching via interactive playback. Behav Ecol Sociobiol 37: 109-117.

Noтteвонм F AND Notтевонм ME. 1978. Relationship between song repertoire and age in the Canary, Serinus canarius. Z Tierpsychol 46: 298-305.

Shackleton SA And Ratcliffe L. 1994. Matched counter-singing signals escalation of aggression in Black-capped Chickadees (Parus atricapillus). Ethology 97: 310-316.
SLATER PJB. 1989. Bird song learning: causes and consequences. Ethol Ecol Evol 1: 19-46.

ToDт D. 1970. Gesangliche Reaktionen der Amsel auf ihren experimentell reproduzierten Eigengesang. Z Vergl Physiol 66: 294-317.

ToDT D. 1971a. Äquivalente und konvalente gesangliche Reaktionen einer extrem regelmässig singenden Nachtigall (Luscinia megarhynchos). Z Vergl Physiol 71: 262-285.

ToDT D. 1971b. Abstraktionsleistung einer gesanglich korrespondierenden abessinischen Erddrossel (Geokichla piaggiae). Z Tierpsychol 28: 59-61.

ToDT D. 1975. Short term inhibition of vocal outputs occurring in the singing behaviour of Blackbirds (Turdus merula). J Comp Physiol A 98: 289-306.

ToDT D. 1981. On functions of vocal matching: effect of counter-replies on song-post choice and singing. $\mathrm{Z}$ Tierpsychol 57: 73-93.

Todt D and Geberzahn N. 2003. Age-dependent effects of song exposure: song organisation sets a boundary between fast and delayed vocal imitation. Anim Behav 65: 971-979.

TodT D and Hultsch H. 1980. Functional aspects of sequences and hierarchy in bird song. Acta XVII Congr Int Orn, Berlin, p. 663-670.

TodT D And Hultsch H. 1996. Acquisition and performance of repertoires: ways of coping with diversity and versatility. In: KRoodsma DE AND Miller EH. (Eds), Ecology and evolution of acoustic communication in birds. Ithaca, NY: Cornell Univ. Press, p. 79-96.

TodT D And Naguib M. 2000. Vocal Interactions in Birds: The Use of Song as a Model in Communication. Adv Study Behav 29: 247-296.

Todt D, Hultsch H And Duvall FP. 1981. Behavioural significance and social function of vocal and nonvocal displays in the monogamous duet-singer Cossypha heuglini. Zool Beitr 27: 421-448.

Wolffgramm J and TodT D. 1982. Pattern and time specificity in vocal responses of blackbirds, Turdus merula. Behaviour 81: 264-286. 